\title{
How Employers Evaluate the Employability of Recent Psychology Graduates: The Case of Chile
}

\author{
Oscar Espinoza $^{1 *}$, Luis González ${ }^{2}$, Luis Sandoval ${ }^{3}$, Noel McGinn ${ }^{4}$ \\ and Paulina Cárdenas ${ }^{5}$

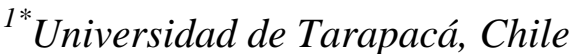 \\ ${ }^{2}$ Programa Interdisciplinario de Investigaciones en Educación, Chile \\ ${ }^{3,5}$ Universidad Tecnológica Metropolitana, Chile \\ ${ }^{4}$ Harvard University, USA \\ 1*oespinoza@academia.cl, ${ }^{2}$ legonzalez.fiegehen@gmail.com, ${ }^{3}$ lsandoval@utem.cl, \\ ${ }^{4}$ nmcginn@igc.org, 5 pcardenas@utem.cl
}

\begin{abstract}
The purpose of this study was to assess employers' perceptions of the job performance of recent Psychology graduates of Chilean universities. There have been few studies of the impact of universities with different admission policies on the value added by their study programs. Not much is known about how the work performance of Chilean psychologists varies according to the type of university in which they were trained. The qualitative research used semi-structured interviews of employers of graduates with less than three years of employment from three universities. Universities selected represent three levels of admission selectivity (low, medium, and high). University officials listed all employers of their graduates. A random sample of 10 employers was interviewed. The employers reported large differences in quality of performance, linked to the university in which the graduate had studied. Graduates of the high selectivity university received the highest ratings. The employers' perspectives suggest that the current education system privileges theoretical knowledge more than knowing how to be and how to do it, although these are the competencies required by current occupations and society in the 21 st century. This finding has important implications: The Low Selectivity University (LSU) and Medium Selectivity University (MSU) can improve their graduates' skills and opportunities by an increased emphasis on generic competencies.
\end{abstract}

Keywords: Chile, Psychology, Graduates, Job performance, Quality of training

\section{Introduction}

Beginning around 1980, the term "employability" came into play to justify employers' preference for some job applicants over others [1]. The introduction of university ranking systems increased attention to employability by universities and by students, first in Anglophone countries than in continental Europe. Once intended to produce "educated persons" for positions of leadership, the mission of the university now, some claim, is to produce "employable persons" [2][3].

Article history:

Received (May 3, 2021), Review Result (July 26, 2021), Accepted (September 1, 2021) 
The Bologna Process in Europe, which gave "employability pride-of-place" [4], sought through the Tuning Project to standardize the competencies that students would acquire in universities. There is, however, considerable disagreement about whether employability should be regarded as a reliable characteristic of university graduates, or whether it is the outcome of a complex process involving unpredictable variables [5][6][7]. These and other authors question the utility of university efforts to elevate the employability of their graduates [4][8].

In Chile, as elsewhere, there is little reliable information about the job performance of graduates and how that can be improved. This lack of understanding makes it difficult to design public policies to support the expectations that new professionals have about their careers. Our ignorance increases the risk of failure and financial loss by families seeking a return from their investment in education. Chile recently established a need-based program to finance higher education, but many students still run up serious debts using bank loans to finance their studies [9][10].

There is ample evidence to support the assertion that persons with higher education, compared to those with lower levels of schooling, are advantaged in the labour market [11] [12][13]. In Chile, this is documented in the results of the annual Supplementary Income survey by the National Statistics Institute [14]. The results are not; however, equivalent for all university graduates. Salary information collected by the Ministry of Education reports that one and four years after hiring indicates significant differences related to the university attended [15]. Available evidence indicates that continued implementation of the employability policy will reproduce rather than reduce Chile's high level of social and economic inequality [16][17][18]. This suggests that the assessment of higher education should also include graduates' level of salary attained and the relationship between the work performed and training [19][20].

Little or nothing is known about the skills that new professionals are acquiring to meet the demands of the labor market. In this scenario, not much is known about how the work performance of Chilean psychologists varies according to the type of university in which they were trained. There have been few studies of the impact of universities with different admission policies on the value added by their training study programs [21][22][23].

The Psychology degree program was chosen for this study because the increasing number of psychologists in the labor force has in recent years exceeded demand [15][24].

The university degree in Psychology was first offered in the early 1960s. In the first five years (1962-1966), approximately 23 Psychologists graduated each year. Thirty years later, that number had jumped to approximately 378. By 2017, universities were graduating more than 4000 Psychologists per year [15].

Given the lack of information, it is reasonable to ask: How do employers see the work performance of graduate psychologists from different universities? The research objective of this study is to compare employers' perceptions of their Psychologist employees according to the level of admission selectivity of the universities from which they graduated.

\section{Literature review}

The task of forming graduates for employment has become more complex, in part because knowledge has expanded as a result of increased access to education, resulting in more technological change, which in turn has prompted new occupations and new fields of study and training. Changes in technology and management theory have resulted in greater 
flexibility in the utilization of human resources, giving employers more options in the hiring of new staff [25].

Research in Europe and the United Kingdom reported that university diplomas or titles were no longer a guarantee of employment. Instead, the transition into the labor force depended on the demonstration of certain competencies [26]. A 2004-2007 study in 16 European countries on employability and professional flexibility (REFLEX) found that one in four university graduates complained that the skills they had acquired were insufficient to earn them acceptable employment [27]. Universities competing for students are pressed to match the profile of knowledge, skills, and attributes of their graduates to a widening range of occupations, many of which are just now being defined. As a consequence, the employability of graduates is said to be a major criterion for assessing the quality of a university [2]. A similar survey, PROFLEX, has surveyed 10,000 university graduates in Latin America. The study concludes that university programs have a significant effect on graduates' capacity for innovation [28].

Note, however, that these assertions imply that employment depends only on the attributes of the candidate. Other research demonstrates clearly that it also is influenced by the actions of the employer and those of other competitors for the available position. Employability is not embedded in an individual but instead is a transactional construct. Universities can affect (some) characteristics of the candidates, individuals can seek certain jobs and not others, and employers can influence characteristics of the "demand" (job requirements) [29][30].

The construct of employability has been discussed from three complementary perspectives, which have been labeled as "possessive", "positional", and "processing" [31]. The possessive approach argues that employers select personnel who will be highly productive. In economic terms, productivity is a function of possessing technical knowledge and skills or human capital. When this theory was first proposed, years of schooling were seen as a reliable indicator of a person's human capital [32]. Some research gives less importance to skills as the basis for employers' decisions [33]. A more common perspective today is that candidates are hired also for their appearance, speech, or behavior, which is interpreted as information about their likely performance in an organization. This approach is called "signalling theory" [34], and the visible behavioral attributes of a person are referred to as cultural capital. Membership in a family, community or organization also influences or results in social relationships, which can facilitate access to and securement of employment. This is known as social capital [35].

The positional view of graduate employability argues that the likelihood of employment of a given individual or category of persons depends on the attributes and actions of other persons [36]. Competition for jobs increases when the expansion of higher education creates credential inflation. Social elites make use of their resources to acquire more prestigious credentials, to position themselves better in the queue for limited high-skilled (and more highly rewarded) vacancies, and therefore, to secure an advantage in the competition [37]. Graduates from working-class backgrounds who, because of their position in society, have less cultural and social capital, are less employable. They are more likely to find employment in non-graduate occupations and to earn significantly less than their middle-class counterparts [38].

The likelihood of employment depends, therefore, not just on the quality of the university's training program but on the efforts of the student or graduate to "manage" their career [39][40]. Beginning with the choice of university, students can seek to improve their future opportunities. For example, in some countries employment opportunities are greater for students attending prestigious universities [41][42]. Once enrolled, students can begin to 
make themselves look like successful occupants of their profession. The development of professional identity can be recognized (and appreciated) by future employers who see the candidate as capable of contributing to the organization [33][43]. Universities can foster career management and the building of professional identity in the degree program curriculum, as part of subject courses, as a separate course, and through practicum and work placement experiences [44]. An effective "identity" can be acquired in school, but some research suggests that only direct work experience has a major effect on employability [43].

Finally, today's graduates vary in the extent to which they are able and willing to adapt to different circumstances. Research from the processing perspective identifies different stages of career development, the knowledge and skills that enable employees to move to the next level, and how employees acquire the awareness of opportunities [45]. Researchers have developed an instrument that measures job applicants' self-confidence, curiosity, self-control, and concern for performance, producing an "Adapt-Ability" scale [46]. These psychological characteristics have been shown to contribute to the employability of a job candidate.

Research on job performance usually has focused on establishing the degree to which the abilities graduates have are those required in the labour force [47][48]. The relationship has been studied looking at salaries [49], work satisfaction, underemployment, workplace conflicts [50], and psychological effects on professional workers [51]. The fit or disjunction between abilities and job requirements has also been studied in graduates of doctoral programs [52].

Graduates with attributes and skills sought by employers can find work without major difficulty and perform adequately on the job [53]. This reflects the relevance and quality of the training they received [47][54].

Among the important skills are those sometimes referred to as non-cognitive, generic (not particular to a discipline), or "soft". They include, among others, communication, critical thinking, capture, and analysis of information, social relationships, self-esteem, and selfunderstanding [38][53][54].

In a competitive labor market, these skills are not directly related to the tasks that defined the occupation but they can command the same or more importance than job-specific abilities [55][56]. As a consequence, although graduates are "well-prepared" (in their discipline) they may not be hired. A study of the employability of new professional graduates, carried out in 16 European countries between 2004 and 2007, found that one in four university graduates complained that the knowledge and skills acquired in their study programs were not sufficient to ensure an acceptable job [57].

Another study, including more than 7000 firms in 27 countries in the European Union, reported that employers put the most importance on skills in teamwork, communication, reading comprehension, writing, computing ability, adaptability in new situations, and problem-solving ability. Significantly, 80 percent of those interviewed were satisfied with the skill levels of the graduates they had hired [58].

In Chile, the work performance of psychologists has been studied from the perspective of practicing professionals and compared with their university training. The results highlight that the lack of generic skills leads to reduce effects on the job [59]. The same conclusion was reached by García and others [60] using a qualitative approach to study psychologists working in primary and secondary education. Using a different methodology, Makrinov and coauthors [61] looked at the work performance of 237 psychologists who had graduated from a highly selective university between 1989 and 1999. Among their findings was that graduates had inadequate training in interpersonal relationships, especially those involved in leadership. They also reported a high turnover in jobs, on average graduates spending only 2 
years in a given position. This study was especially important as it tried to identify a more direct relationship between training and job performance of psychologists. None of the three studies identified inadequate training in specific discipline-based work skills.

In summary, the study reported here is a first attempt to relate employers' perceptions of the job performance of psychologists they have hired to the selectivity of the university in which the psychologists were trained.

\section{Methodology}

This study followed a qualitative research design. This design is appropriate because the focus of the study is on understanding employers' perceptions of the professional performance of graduates of the Psychology program. Data was collected using a semi-structured interview method. Fieldwork was carried out between January and September 2017, in the Metropolitan Region of Chile.

Interview data were subjected to content analysis [62]; inductive categories were developed working with the interview transcripts. The categories were constructed to be consistent with the objectives of the study. The analysis focused on the employers' perception of the characteristics of employability of candidates, and their inferences concerning the candidates' training.

These perceptions were arranged in four categories:

(a) University training;

(b) Professional performance competencies;

(c) Ethics and values compatible with the quality of performance; and

(d) Skills required for different settings and situations.

Most of the employers' comments were expressed in colloquial, 'street' Spanish. This has been translated into English more accessible to the general public. Content Analysis was used applying inductive categories. These aid in the categorization of the employers' perceptions of the graduates.

The sample of employers interviewed was intentional, including 10 persons selected from a group that in the present or past had a working relationship with psychologists who had graduated from one of the three universities in the sample. Three interviews were conducted with employers of psychologists from the low selectivity university, 4 with employers of psychologists from the medium selectivity university, and 3 with psychologists from the high selectivity university.

The level of selectivity of the universities included was based on the years of accreditation of each institution, and scores on the national University Selection Test (PSU) required for admission. The PSU has an average score of 500 and a standard deviation of 100.

Using these criteria, the selected institutions had the following characteristics:

(a) High Selectivity (HSU). For the years 2012, 2103, and 2014, the average attained PSU score of 660 .

(b) Medium Selectivity (MSU). For the years 2012, 2013, and 2014, the average attained PSU score of 476.

(c) Low Selectivity (LSU). For the years 2012, 2013, and 2014, the average attained PSU score below 400 . 
Confidentiality of respondents has been protected by identifying each of the paragraphs of their narrative with the following coding scheme: the individual employers were assigned a number (E1 to E10); the selectivity of the university in question was indicated as UAS (High), MSU (Medium), or LSU (Low); and the gender of the employer as feminine (F) or masculine (M).

\section{Results}

Results, in the form of employers' perceptions or opinions, grouped under the four categories listed in the Methodology section, that is: University training, Professional performance, Ethics and values compatible with the quality of performance, and Skills required in actual job situations

\subsection{University training}

This concerns the employers' evaluation of the technical, theoretical, and methodological training that graduates demonstrated in their job performance.

The employers agreed that the LSU graduates' preparation in the use of psychometric instruments was weak. In addition, the training methods were not up to date. This did not, however, reduce their perceived level of professional performance. On the other hand, the employers referred positively to the graduates' soft skills, in the sense that the LSU graduates tried hard to perform well on the job. This was attributed by the employers to the social profile of graduates from that university.

That is to say, they have the basic knowledge, but that is not optimal. [One would hope] that they could manage a larger and more up-to-date pool of tests or psychometric methods. They are following the results of tests from two decades ago $(E 1-L S U-F)$.

I attribute [the issue of lack of more transversal skills] in this case to the "house of studies" in which they were formed (...) which has a lot to do with the socio-economic profile "C3" [medium low]. ${ }^{2}$ To that one adds, besides, the issue of the effort of being the first generation of professionals in their families $(E 1-L S U-F)$.

They come well prepared for the school environment, with skills in handling networks, interruptions, fights...But, in the work on applying instruments (...) they were a bit more lost. But this is a technical thing, which they can learn. For us it is more important than the professional connection with the students (...) It seems to me that the distinguishing mark that these professionals have is their closeness to their students, without ignoring the issue of the diagnostics $(E 3-L S U-F)$.

In the case of graduates from the MSU, the employers' emphasis was on the scarce training they appeared to have received in some dimensions of human resources; both technical and theoretical weaknesses are noted. At the same time, the employers, most of whom are in community organizations, were content with these graduates. They indicated that they are well enough prepared to develop satisfactorily in the work setting. They did note, however, their lack of rigor in the use of various techniques. This was attributed to their lack of training.

\footnotetext{
${ }^{2}$ Chile categorizes individuals in five income levels. C3 is equivalent to US\$12,000 per year and is medium-low.
} 
[the graduates of the MSU] arrive with low general knowledge. For example, in Human Resources, you can see that [they do not know] (...) they are determined enough to want to get ahead, but there are areas requiring knowledge in which they are weak (...) one can see that they lack technical and theoretical knowledge (E 1-MSU -M).

Look, what we are looking for is a community orientation, as I was telling you (and this orientation we find) in the graduates of the $M S U(E 2-M S U-F)$.

[the graduates of the MSU] I think show strengths informative terms. I see a much more social focus, they have it well set and are more conscious about holding a critical social posture. They are people who understand community work, they have covered a lot of ground and life to clinical practice, but clinical from the community perspective. On the other hand, thinking about their failings, I have noted, principally in the beginning, certain failings about a more technical or theoretical perspective, we could say (...) a lack of rigor ... (E $3-M S U-$ F).

In general, the majority of employers of the HSU graduates don't refer specifically to their academic training; instead, they allude to their distinguishing characteristics or graduate profile. This is revealed in the attitudes of the employers - in the organizational and community areas - about the work of these professionals. The graduates (of the HSU) are seen as having an orientation and general focus, a culture that plays a fundamental role in their professional work. Their formation is compared (favorably) with that of graduates from other universities, even of high selectivity, that does not have the same profile.

For his part, the employer from the consulting area also comments on the graduates' technical training which, even if not of top quality, is seen as positive and more balanced than that characteristic of graduates from other universities. The comments that follow support these assertions:

[These professionals have a] more matching technical training, to describe it in one way (...) as if they had an education more adequate in everything (E $1-H S U-M)$.

I like the profile of the psychologist from the HSU because he is more grounded, more about doing things (...) They are more "let's move ahead" and that is truly very pleasing. So, they have this idea, from the beginning, that one has to jump into the fight (E $2-H S U-M)$.

\subsection{Evaluation of professional competences}

This dimension includes the opinions of employers about the competencies of the graduates to meet the expectations and objectives of each of their organizations. The evaluation of the professional performance of the LSU graduates emphasizes their perceived weaknesses in the "technical" aspect of their work, independent of what they can learn quickly and incorporate into their performance. Even so, they are valued for their commitment to their job.

Their failures are more related to technique, but this issue can be straightened out and changed by working (E1-LSU -F).

I feel they lack soft skills (...) They had difficulties (...) in the area of group relationships, interpersonal relationships, which were (...) getting better in time and (...) in some moments it was not so difficult. I believe that many variables come into play, but there was an issue [difficulty] with the soft skills on (...) the arrival of the team (E2 - LSU $-M)$.

In the case of employers of MSU professionals, the graduates hired showed theoretical weaknesses that had to be reinforced by the organizations themselves. It stands out, on the 
other hand, that they are characterized by being active, but this distinction is affected by their limited social abilities, which isn't the fault of the university but rather where they come from. This speaks well of the graduate profile which prepared them for community work on the ground, along with the ability to form adequate connections with their clients.

The following quotes illustrate this:

Three or four professionals have come from the MSU in recent years. They come with failings in knowledge. I see it in (...) how much help they need to be able to work autonomously in the job, [because] these psychologists ask you for training. But two parallel things happen. They begin to work and continue making mistakes despite the training, and that makes you aware that...they don't get it [understand] and they don't dare to tell you so. And the other issue is that they stop asking questions to not appear that they don't know; this leads to constant errors, a repetition of mistakes, so you become aware that at the core they are not $\operatorname{good}(E 1-M S U-M)$.

They are hardworking, they are people that want to do better (...) [however] the good impression of being persevering (...) gets tarnished when they start with attitudes that act against the workplace climate in which you are; [which manifests itself] ... since they don't know how to converse, because anything you say to them is resented, until there are attitudes or actions tied up with ethics, loyalty, with commitment, that type of thing. (...) I don't know if it is the university or something from the crib $(E 1-M S U-M)$.

I have seen certain failings in them more to technique and methodology, in analysis and organization of information, writing of reports and memos, etc. (...) They lack a little theoretical baggage, I believe (E $3-M S U-F)$.

The opinions of the employers of the HSU graduates focused on aspects related more to generic competencies than to those based on the disciplines. In both the consulting office and in the community, they believe that the graduates' training has been adequate, but they emphasize that for their introduction to work to be successful and lead to good performance, they require more personal skills, rather than more technical and theoretical training. The employer from the organizational area varied in his judgment depending on the graduate psychologists' specialization. Those who had been trained in labor psychology were evaluated positively, but the employer was critical of those trained in clinical psychology, believing they need the training to make up for various gaps. This same employer thought that overall the graduates had good basic training.

[The psychologist from the HSU] coordinated the information coming out of the development of the projects (...) which consisted of assessing whether the information found in the questionnaires was correct (...) I think that she had a very good profile for the job that she was carrying out $(E 1-H S U-F)$.

[With respect to their professional development] I have to separate the graduates into two groups: those that are labor psychologists, who have, in general, got ahead very well; but those that are clinicians, we have had to reconvert (...). But in general, the professional evaluation is very positive, technically they are good, one sees that they know, one sees they have had good training ( $E 2-H S U-M)$.

I could tell you that the HSU psychologist has a broadly adequate and satisfactory performance inside the team of professionals. He stands out for his contributions, he is a very good professional, very willing. Besides, in the work, he contributes with plenty of ideas. He has been a good contributor ( $E 3-H S U-F)$. 


\subsection{Ethics and values}

The concern here is the relationship between the set of norms and principles that delineate a correct attitude and quality performance. Their coherence strengthens the professional image as well as the image of the institution.

The employers generally feel that the values of the LSU graduates are weak, which affects their image and the quality of their work performance.

[They fail in] some very small things, such as notifying that you are going to arrive or not or calling in 10 minutes before the start of a session to say that they are sick, super simple things. In this work there is a lot of responsibility for the welfare of the patient, so not coming to work or waiting until 10 minutes before the session to inform that they are not coming, I consider enormously irresponsible (E 1- LSU-F).

The behavior of [some graduate psychologists of the LSU] without doubt generates difficulties and friction with people because I have received comments about some professionals that have been laid out (...) [that] (...) certain ways of relating with respect to asking things and making statements are not appropriate. It's not a question of a particular form of bad behavior, I've looked at it and it's not so, but there is the issue of how people feel when they are asked for something (E 2- LSU-M).

In the case of employers of professionals from the MSU, on the one hand, reference is made to their appreciation of the effort and commitment the graduates have. But on the other hand, the employers are critical of the MSU graduates' inadequate behavior in an organization, and their incapacity to develop professional criteria that match the quality of their work.

The majority are kids that have a common characteristic, they are eager to get ahead but have problems with their level of knowledge and with their value system, where they are weak (E $1-M S U-M)$.

They have attitudes and act in ways that conflict with values such as loyalty and commitment, that kind of thing. Run down the boss [try to get him fired] to give you a practical example, begin to overload him with issues unrelated to the job, so I see a weakness in this type of person that comes from that university $(E 1-M S U-M)$.

In this aspect, the employers of psychologists from the HSU are positive in their assessments. They emphasize the graduates' reliability, productivity, and desire to do satisfactory work, to help work teams with whom they are connected. The following remarks illustrate that position:

He always answered and on that basis, I always had total trust in the work that he was going to carry out (...) and if we had some typical problems at the end of the analysis, for example, if something was missing. I could count on him doing a comparatively good job (E1$H S U-F)$.

Yes, but here leadership rises (...) emerges from the group (...) They can run their projects by themselves, but with the help of the rest of the team, in some way leadership is generated within the team (...) because there's no struggle for power (...) but at the same time it generates a lot more synergy and connectivity within the group and makes it possible for them to contribute horizontally (E2-HSU-M). 


\subsection{Skills required for current work settings}

This dimension refers to the generic abilities required to analyze problems, generate proposed solutions, promote required changes, and apply the knowledge acquired both in professional training as well as in the work career.

The predominant opinion of employers of graduates of the LSU is that the university does not adequately develop these competencies sufficiently for their graduates to be flexible and able to adapt in a context of constant change. They cannot also perform in different settings and articulate interests and stages.

I believe that in their formation current graduates of different universities did not receive adequate training for working with and in groups, which makes them anxious (...) They had nothing on working with groups of patients nor with how to handle the stress of clinical rounds. These are situations they will experience whether in a public health center or a private clinic. The administration part can be learned later (...) but they don't leave wellprepared.

[These psychologists] have to deal with the difficulties of a community mental health program.... where you face problems every day. (...) There, the person in charge of the program gets in the car and leaves, so you have to be proactive and resilient in the face of those challenges ( $E 2$ - LSU $-M$ ).

Employers of the MSU graduates see these professionals as lacking soft skills, for example in the kind of leadership they show, which makes it difficult to achieve the kind of balance that makes a collaborative style possible. They also underline that it would be costly to change to work settings that would alter the logic and variables to be considered by the various actors in the decision process. They report that the graduates are excessively critical of the institutions in which they work, which reflects on their performance. On the other hand, they appreciate the good treatment the graduates provide their clients, recognizing their capacity for empathy.

Another employer noted satisfaction by identifying the fundamental competencies that lead to optimal performance, acknowledging the proactivity of these graduates:

All those who have come from the MSU have ended up confessing to me that when they arrived they listened and were surprised by what they found here, but if you talk statistics to them and scare them, they die of fright but later they can tell me, for example when they have been here six months, "this question was all Greek to me (...)

[With regard to leadership] ...I can tell you about one of the psychologists I was supervising whose turn came up to lead other psychologists that had been her classmates in the university. In the beginning, she relied on participatory leadership, but at the first sign of friction that stopped and changed into despotic leadership... and instead of resolving the conflict she adopted a more confrontational attitude (...) (E1-UMS-M).

You have to work down on the street, in the community (...) link up with the base social organizations, work with the youth in their setting, [give] psychotherapy but on the street (...) I think that the professionals that come from the MSU (...) are mostly from the low social strata, and therefore are not afraid of the setting (E4-MSU $-M)$.

The employers of HSU graduates note their communicative abilities, their productivity, their work in networks, commitment, flexibility, and capacity to adapt themselves to different contexts. They also value their motivation to improve their learning and constantly innovate. The idea occurs to one employer that universities are not preparing people for the world of 
work, but rather fundamentally are locating them, in a skewed manner, in the world of knowledge.

They always are willing to take on different kinds of work, without major complaints (...) I have not seen this in [graduates from] other kinds of universities. Besides, their technical training is more appropriate. You see that they had a better all-around education, but as recent graduates in their field, they don't have deep knowledge in anything, so when you want to involve them in a project, you have to teach them, but they learn and learn quickly (E 2$H S U-M)$.

...Their performance is broadly adequate and satisfactory (...) They distinguish themselves by their contributions, both in their training and their characteristics (...)

They have certain personal characteristics that make them very good workmates, very professional, and willing to take on anything, but besides the work and training (...) they have lots of ideas, they are innovators, creative, they apply their knowledge to the job. They have, therefore, been a good addition (E 3-HSU-F).

They indicate that employers place importance on graduates being capable of adapting to different work settings and organizational strategies. This is linked to the job candidates' capacity for leadership and adaptability to change. While these could be understood as generic competencies, these are featured by employers in the context of changing conditions of work. The employers thought that graduates from all three universities were not well prepared in this regard.

[Figure 1] summarizes the main findings associated with the perceptions of employers of graduates of psychology majors.

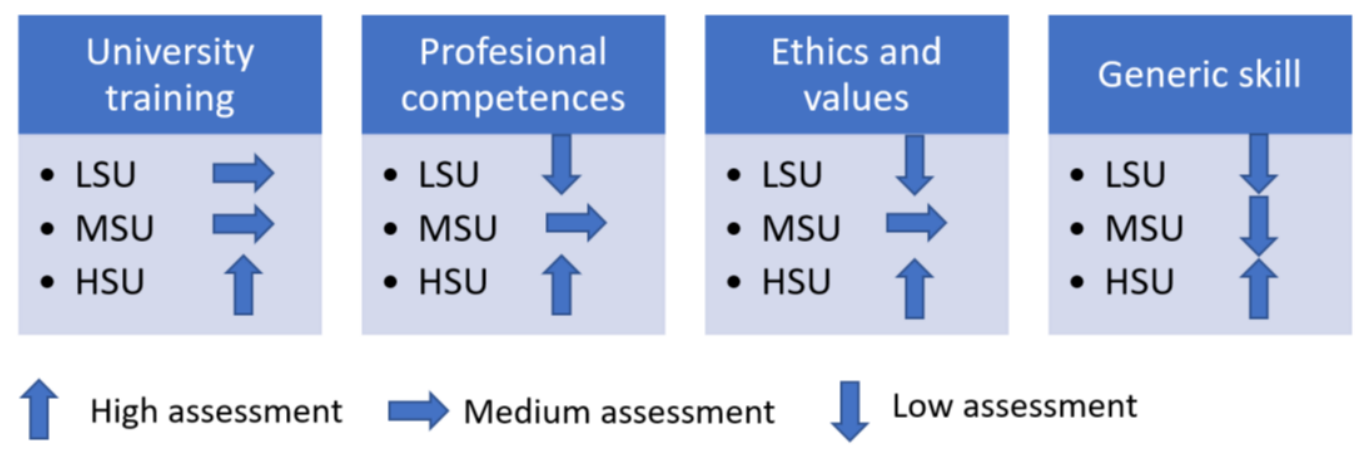

Figure 1. Summary of findings on employer assessments

\section{Discussion}

One finding is the importance that employers assign to generic competencies. The weaknesses identified are principally in the domain of generic competencies, which is what limits the optimal professional development of the psychologists who graduated from LSU and MSU. This is not, however, the case for HSU graduates, who demonstrate fundamental skills for good work performance. Perhaps the HSU graduates have a superior level of socialcultural capital since it is known that university selectivity is based on the socio-economic and cultural level of applicants. This is consistent with Coleman`s study [35].

Another factor to take into account is the work setting experienced by the new psychologists. It is possible that the graduates of the LSU and the MSU were placed in situations more complicated and demanding than what they had been trained to handle. The 
work contexts for the HSU graduates were perhaps more favorable, enabling them to learn more quickly on the job, which would bias employers' perceptions. This conclusion is consistent with the findings reported for other professional fields in Chile [18].

The employers' perspectives suggest that the current education system privileges theoretical knowledge more than knowing how to be and how to do it, although these are the competencies required by current occupations and society in the 21 st century. Considering the soft skills and competencies demanded in the labor market, it can be said that the more positive evaluation of graduates of the HSU is influenced by their disciplinary and technical training. The LSU and MSU universities can improve their graduates' opportunities by an increased emphasis on these competencies, which usually are included within general training. As far as soft skills are concerned, these results are consistent with the findings of Balcar [55] and Heckman and others [56].

Another caution concerning the findings is to keep in mind that the employers' perceptions are based on graduates' performance in a recent, concrete situation. They say nothing about the development of competencies required in the future. Current opinions should be compared with expert judgments about possible future performance. For example, the World Economic Forum, as well as Humburg and Van der Velden [63], list the skills currently required for employment.

The employers view these graduate Psychologists as varying in their level of competence as well as institutional identity. Each one of them may find employment in a given context, but they are not equally well-prepared for their fields and would not be considered to be equally employable for all jobs. In terms of quality, however, each program has produced graduates who have been effective in the jobs they have taken. In principle, the programs are of the right quality for the public they seek to serve. On the other hand, this reality preserves the social inequalities of the labor market, as described by Puga, Polanco, and Corvalán [18].

\section{Conclusions}

Based on the interviews carried out it can be concluded that employers in Chile do not think that the three universities studied offer the same quality of training in their Psychology degree programs. Employers distinguished between graduates from the three universities on two dimensions. First, those from the non- and moderately-selective universities generally were characterized as having had incomplete training in theory and technical skills. That is, candidates from these two universities did not meet all the requirements in the job profile. Some psychologists, for example, had not been trained in the application of the latest version of a children's intelligence test. Others were not familiar with a particular statistical test. Lack of specific conceptual or practical knowledge and skills were attributed to their training program (or university), and not described as reflecting the graduates' level of intellectual ability. In other words, the graduates were educated, but not a perfect fit for the job.

This should worry the State. The failure to provide all graduates with the human capital required by the labor market affects in some measure the equality of opportunity in employment. The principal effect is about those successful work efforts that result in permanence and promotion in the work setting.

In the first order of importance is the improvement of the kind of training given to students who arrive with lower levels of cultural capital. This could be done with the intent of ensuring their stability on the job once employed and raising their employability to the level of those students who come from social sectors that offer greater educational resources. 
Another disturbing feature noted by the employers is ethical and value training. The psychology graduates show deficiencies in this area. The employers of the LSU and MSU graduates clearly stated their dissatisfaction in this regard. In the case of the HSU graduates, on the other hand, employers remarked on the confidence they feel that the graduates will comply with specified codes of conduct. This difference also is probably related to the socialcultural capital of the graduates.

In third place, satisfaction with the performance of graduates varied significantly across the work setting. Graduates from the non and moderately selective universities performed much better in situations with which they were familiar by their socio-economic background.

The findings raise another concern, that universities can or will have little effect carrying out this kind of training. This is a fundamental issue to be addressed, perhaps requiring specific steps to ensure that training programs include, and succeed in developing, awareness of ethical and value concerns and actions in the profession. While it is true that these values are (or are not) learned in the family context, they could be reinforced by universities, as a basic element of those characteristics considered in awarding the professional degree. These aspects should be considered in future research.

\section{Limitations of this Study}

The results may not be generalizable to Chile or elsewhere, as the employers are not a statistically representative sample of all employers of psychologists. As they were recommended by the universities, their opinions may be favorably biased. In that case, graduates from these institutions may have even fewer generic and specific competencies than the employers stated, especially those from LSU and MSU. The study does not indicate the validity or reliability of the data provided by employers. The interviews with employers made clear that many subjective factors enter the hiring process. A much larger sample of employers would be required to attain a reasonable level of reliability for the data.

\section{Funding}

This research was supported by the National Agency of Research and Development of Chile (ANID) through the FONDECYT Project $\mathrm{N}^{\circ} 1151016$. The authors are solely responsible for the contents of this report.

\section{Acknowledgement}

We appreciate the support given by the Instituto Interuniversitario de Investigación Educativa (IESED-Chile)

\section{References}

[1] R. McQuaid and C. Lindsay, “The concept of employability,” Urban Studies, vol.42, no.2, pp.197-219, (2005) Retrieved from: https://pureportal.strath.ac.uk/files-asset/12212609/Concept_of_Employability_FINAL.pdf

[2] T. McCowan, "Should universities promote employability?" Theory and Research in Education, vol.13, no.3, pp.267-285, (2015) Retrieved from http://discovery.ucl.ac.uk/1498957/1/Should universities promote employability, author draft.pdf

[3] A. Schleicher, "Value-added: How do you measure whether universities are delivering for their students?" (2016), Retrieved from http://www.hepi.ac.uk/wp-content/uploads/2016/01/Andreas-Schleicher-lecture1.pdf

[4] C. Sin and G. Neave, "Employability deconstructed: Perceptions of Bologna stakeholders," Studies in Higher Education, vol.41, no.8, pp.1447-1462, (2014), DOI: 10.1080/03075079.2014.977859\#.VPmMGS5 
[5] S. Cranmer, "Enhancing graduate employability: Best intentions and mixed outcomes," Studies in Higher Education, vol.31, no.2, pp.169-184, (2006), DOI: 10.1080/03075070600572041

[6] M. Tomlinson, "Graduate employability: A review of conceptual and empirical themes," Higher Education Policy, vol.25, no.4, pp.407-431, (2012), DOI: 10.1057/hep.2011.26

[7] J. Noonan and M. Coral, "The tyranny of work: Employability and the neoliberal assault on education," Alternate $\quad$ Routes, vol.26, pp.51-73, (2015), Retrieved from http://scholar.uwindsor.ca/philosophypubhttp://scholar.uwindsor.ca/philosophypub/41

[8] F. Suleman, "The employability skills of higher education graduates: Insights into conceptual frameworks and methodological options," The Journal of International Higher Education Research, vol.76, no.2, pp.263278, (2018)

[9] M. Canales, A. Opazo, and J. Camps, "Leave the room. Youth expectations in Chile today," Ultima Década, vol.44, pp.73-108, (2016)

[10] T. Flores and R. Fernández, "Advances in higher education in Chile: Coverage and completion of studies in the world of work," Documento de Trabajo N¹, Observatorio de la Educación Superior, OBESUP: Santiago, Chile, (2017)

[11] A. Mizala and P. Romaguera, "Remuneration and rates of return of Chilean professionals," In J. Brunner and P. Meller P (eds), Oferta y demanda de profesionales y técnicos en Chile, RIL editores: Santiago, Chile, pp.184-190, (2004)

[12] G. Psacharopoulos and H. Patrinos, "Returns to investment in education: A decennial review of the global literature,” Education Economics vol.26, no.5, pp.445-458, (2018), DOI: 10.1080/09645292.2018.1484426

[13] V. Riquelme and V. Olivares, "Labor profitability in Chile: Analysis of the evolution of returns by educational level," Ciencia and Trabajo, vol.17, no.52, pp.69-76, (2015)

[14] Instituto Nacional de Estadísticas, "Supplementary income survey,” INE: Santiago, Chile, (2018)

[15] MINEDUC-SIES, "Statistic psychology,” (2019)

[16] O. Espinoza, L. González, N. McGinn, D. Castillo, and L. Sandoval, "Family background, secondary school, and university Elitism: Contributors to income inequality in Chile," Issues in Educational Research vol.28 no.4, pp.918-939, (2018b)

[17] PNUD, (2017) "Unequal. Origins, changes, and challenges of the social gap in Chile," United Nations Development Program: Santiago, Chile, (2017)

[18] I. Puga, D. Polanco, and D. Corvalán, "Segregation of training and teaching and its role in the social reproduction of inequality," Quality in Education, vol.43, pp.57-102, (2015)

[19] O. Espinoza and L. González, "Equity in the higher education system in Chile: Access, permanence, performance and results," In A. Bernasconi (ed), Higher Education in Chile: Transformation, Development, and Crisis, Editions of the Catholic University of Chile: Santiago, pp.517-580, (2015)

[20] L. González, Ó. Espinoza, N. McGinn, L. Sandoval, and D. Castillo, "The limited value of "Employability" as an objective in the training of psychologists: Evidence from Chile," Journal of Teaching and Learning for Graduates Employability, vol.11, no.1, pp.50-62, (2020)

[21] O. Espinoza, L. González, and J. Loyola, "Evaluation of the satisfaction of Psychology degree graduates in Chile", Educational Innovation, vol.18, no.76, pp.171-192, (2018a)

[22] O. Espinoza, N. McGinn, L. González, L. Sandoval, and D. Castillo, "Factors that affect post-graduation satisfaction of Chilean university students," Studies in Higher Education, vol.44, no.6, pp.1023-1038, (2019a)

[23] O. Espinoza, N. McGinn, L. González, L. Sandoval. and D. Castillo, "Education and employment in two Chilean undergraduate programs," Education + Training, vol.61, no.3, pp.326-341, (2019b)

[24] O. Espinoza and L. González, "The Crisis of the Chilean Higher Education System and the Decline of the Neoliberal Model,” Policy and Equity Barometer, vol.3, pp.94-133, (2011)

[25] P. Brown and H. Lauder, "Globalization, international education, and the formation of a transnational class?" Yearbook of the National Society for the Study of Education vol.108, no.2, pp.130-147, (2009) 
[26] M. Lindberg, "At the frontier of graduate surveys. Assessing participation and employability of graduates with master's degree in nine European countries," Higher Education, vol.53, vol.5, pp.623-644, (2007) DOI: 10.1007/s10734-005-1672-4

[27] J. Allen and R. van der Velden, "Educational mismatches versus skill mismatches: Effects on wages, job satisfaction, and on-the-job search," Oxford Economic Papers, vol.3, pp.434-452, (2001)

[28] L. Vila, C. Dávila, and J. Mora, "Competencies for innovation in Latin American universities: an empirical analysis," Ibero-American Journal of Higher Education, vol.1, no.1, pp.5-23, (2010)

[29] M. Tomlinson, "Graduate employability and student attitudes and orientations to the labor market," Journal of Education and Work, vol.20, no.4, pp.285-304, (2007)

[30] M. Clarke, "Understanding and managing employability in changing career contexts," Journal of European Industrial Training, vol.32, no.4, pp.258-284, (2008), DOI: 10.1108/03090590810871379

[31] B. Okay-Somerville and D. Scholarios, "Position, possession or process? Understanding objective and subjective employability during university-to-work transitions," Studies in Higher Education, vol.42, no.7, pp.1275-1291, (2015), DOI: 10.1080/03075079.2015.1091813

[32] S. Sweetland, "Human capital theory: Foundations of a field of inquiry," Review of Educational Research vol.66, no.3, pp.341-359, DOI: 10.3102/00346543066003341

[33] G. Hinchliffe and A. Jolly, "Graduate identity and employability," British Educational Research Journal vol.37, no.40, pp.563-584, (2011), DOI: 10.1080/01411926.2010.482200

[34] Humburg, M. van der Velden, and A. Verhagen, "The employability of higher education graduates: The employers' perspective," Luxembourg: Publications Office of the European Union, (2013) DOI: $10.2766 / 54258$

[35] J. Coleman, "Social capital in the creation of human capital," The American Journal of Sociology, vol.94, pp. $95-120$

[36] G. Tholen, "The social construction of competition for graduate jobs: A comparison between Great Britain and the Netherlands," Sociology, vol.47, no.2, pp.267-283, (2013), DOI: 10.1177/0038038512444815

[37] P. Brown, A. Hesketh, and S. Williams, "Employability in a knowledge-driven economy," Journal of Education and Work, vol.16, no.2, pp.107-126, (2003), DOI: 10.1080/13639080305562

[38] S. Kalfa and L. Taksa, "Cultural capital in business higher education: reconsidering the graduate attributes movement and the focus on employability," Studies in Higher Education, vol.40, no.4, pp.580-595, (2015) DOI: $10.1080 / 03075079.2013 .842210$

[39] Llanes, J. P. Figuera, and M. Torrado, "Employability and career management of graduates in Pedagogy," Spanish Journal of Orientation and Psychopedagogy, vol.28, no.2, pp.46-60, (2017)

[40] McGrath, S. R. Madziva, and J. Thondhlana, "Rethinking the employability of international graduate migrants: Reflections on the experiences of Zimbabweans with degrees from England," Journal of Further and Higher Education, vol.41, no.2, pp.238-259, (2017), DOI: 10.1080/0309877X.2015.1062853

[41] D. Ciriaci and A. Muscio, "University choice, research quality, and graduates' employability: Evidence from Italian national survey data," European Educational Research Journal, vol.13, no.2, pp.199-219, (2014), DOI: 10.2304/eerj.2014.13.2.199

[42] N. Drydakis, "The effect of university attended on graduates' labor market prospects: A field study of Great Britain," Economics of Education Review, vol.52 (C), pp.192-208, (2016), Retrieved from https://econpapers.repec.org/article/eeeecoedu/v_3a52_3ay_3a2016_3ai_3ac_3ap_3a192-208.htm

[43] D. Jackson, "Developing pre-professional identity in undergraduates through work-integrated learning," Higher Education, vol.74, no.5, pp.833-853, (2017)

[44] M. Yorke and P. Knight, "Embedding employability into the curriculum," Learning and Employability Series vol.3, pp.1-28, (2004), DOI: 10.1108/17561391111106016

[45] A. Watts, "Career development learning and capability," Heslington, York, UK: Higher Education Academy, (2006), Retrieved from https://www.heacademy.ac.uk/system/files/esect_career_development_learning_and_employability.pdf 
[46] M. Savickas and E. Porfeli, "Career adapt-abilities scale: Construction, reliability, and measurement equivalence across 13 countries," Journal of Vocational Behavior, vol.80, no.3, pp.661-673, (2012) DOI: 10.1016/j.jvb.2012.01.011

[47] K. Matsouka and D. Mihail, “Graduates' employability: What do graduates and employers think?” Industry and Higher Education, vol.30, no.5, pp.321-326, (2016)

[48] S. McGuinness, K. Pouliakas, and P. Redmond, "Skills mismatch: Concepts, measurement and policy approaches,” Journal of Economic Surveys, vol.32, no.4, pp.961-1220, (2018), DOI: 10.1111/joes.12254

[49] L. Mateos and M. Salinas-Jiménez, "Skills use in the workplace and its effects on wages and job satisfaction: An application to the Spanish case," Personnel Review, vol.47, no.2, pp.494-516, (2018)

[50] G. Quintini, “Over-qualified or under-skilled: A review of existing literature,” OECD Social, Employment and Migration Working Papers, N121, OECD Publishing: Paris, (2011)

[51] A. Shevchuk, D. Strebkov, and S. Davis, "Skill mismatch and work-life conflict: The mediating role of job satisfaction," Journal of Education and Work, vol.32, no.2, pp.181-195, (2019), DOI: 10.1080/13639080.2019.1616281

[52] S. Kim and S Choi, "The effects of job mismatch on pay, job satisfaction and performance," Journal of Open Innovation, Technology, Market and Complexity, vol.4, no.49, pp1-13, (2018)

[53] E. Pereira, M. Vilas-Boas, and C. Rebelo, "University curricula and employability: The stakeholders' views for a future agenda," Industry and Higher Education (First Published February 13, 2020), DOI: $10.1177 / 0950422220901676$

[54] M. Clarke, "Rethinking graduate employability: The role of capital, individual attributes, and context," Studies in Higher Education, vol.43, no.11, pp.1923-1937, (2018)

[55] J. Balcar, "Is it better to invest in hard or soft skills?" The Economic and Labor Relations Review, vol.27, no.4, pp.453-470, (2016)

[56] J. Heckman, J. Stixrud, and S. Urzua, "The effects of cognitive and non-cognitive abilities on labor market outcomes and social behavior," National Bureau of Economic Research: Cambridge, MA., (2006), Available at: http://www.nber.org/papers/w12006

[57] J. Allen and R. Van der Velden, "The flexible professional in the knowledge society: Required competences and the role of higher education,” Springer: New York, (2011), DOI: 10.1007/978-94-007-1353-6_2

[58] European Commission, "Employers' perception of graduate employability," Survey conducted by The Gallup Organization, Hungary upon the request of Directorate-General for Education and Culture, European Commission: Paris, (2010), Available at: https://ec.europa.eu/commfrontoffice/publicopinion/flash/fl_304_en.pdf (accessed 20 December 2019)

[59] M. González, I. González, and K. Vicencio, "Description of the self-perceived role of the psychologist and its implications in the processes of undergraduate training," Psychoperspectives, vol.13, no.1, pp.108-120, (2014)

[60] C. García, G. Carrasco, M. Mendoza, and C. Pérez, "Role of the psychologist in private paid establishments in greater concepción, Chile: A process of co-construction," Pedagogical Studies, vol.38, no.2, pp.169-185, (2012)

[61] N. Makrinov, J. Scharager, and L. Molina, "Current situation of a sample of psychologists graduated from the Pontificia Universidad Católica de Chile,” Psykhe, vol.14, no.1, pp.69-77, (2005)

[62] K. Krippendorff, "Content analysis," In E. Barnouw, G. Gerbner, W. Schramm, T. Worth, and L. Gross (Eds.), International encyclopedia of communication (vol.1), Oxford University Press: New York, NY, pp.403-407. Available at: http://repository.upenn.edu/asc_papers/226

[63] M. Humburg and R. Van der Velden, "What is expected of higher education graduates in the 21st century?" In J. Buchanan, D. Finegold, K. Mayhew, and C. Warhurst (eds), Oxford Handbook of Skills and Training Oxford, Oxford University Press: UK, pp.517-580, (2017) 